\title{
REFORMAS TRABALHISTAS E SEUS MERCADOS: uma comparação Brasil-França
}

\author{
Adalberto Cardoso * (http://orcid.org/0000-0002-6539-0770) \\ Christian Azaïs ** (https://orcid.org/0000-0002-2521-166X)
}

\begin{abstract}
As reformas recentes na legislação trabalhista de Brasil e França abriram uma porta para a comparação. A rationale que as presidiu tem inspiração comum: a flexibilização das formas de uso do trabalho em países nos quais a legislação era reputada muito rígida, dificultando o ajuste das empresas às mudanças constantes na competitividade mundial. Embora Brasil e França ocupem lugares muito distintos na divisão internacional do trabalho, e sofram pressões competitivas também distintas, os motivos alegados pelos reformadores dos dois lados são espantosamente semelhantes. Modernização das relações de trabalho, geração de empregos (e combate ao desemprego), crescimento econômico, melhoria da renda dos trabalhadores e das condições de trabalho. Mas a promessa de segurança socioeconômica vem acompanhada de formas de regulação que geram, na verdade, insegurança no emprego, na renda e nos direitos trabalhistas. O estudo procura avaliar algumas dimensões dessa insegurança, comparando os dois países em torno da noção de "precariedade”.
\end{abstract}

PALAVRAS-CHAVE: BRASIL. França. Reforma trabalhista. Insegurança socioeconômica. Precariedade.

\section{INTRODUÇÃO}

O ano de 2017 será lembrando pelos estudiosos do mundo do trabalho, no Brasil e na França, como aquele em que os trabalhadores do setor privado mais perderam direitos na história recente dos dois países, ao menos até aquela data. ${ }^{1}$ Nunca a legislação trabalhista sofreu mudança tão abrangente e drástica em espaço tão curto de tempo. ${ }^{2}$ Em março, o

\footnotetext{
* Universidade do Estado do Rio de Janeiro (UERJ). Instituto de Estudos Sociais e Políticos (IESP).

Rua da Matriz 82, Botafogo. Cep: 22260-100. Rio de Janeiro - Rio de Janeiro - Brasil. acardoso@iesp.uerj.br

* * Laboratoire Interdisciplinaire pour la Sociologie Economique. Conservatoire National des Arts et Métiers - LISE - CNAM) 1LAB40.

2 Rue Conté, 75003. Paris. christian.azais@lecnam.net

${ }^{1}$ Adalberto Cardoso agradece ao Conselho Nacional de Desenvolvimento Científico e Tecnológico (CNPq) pela bolsa de Pesquisador Visitante Sênior no Exterior, para o período de agosto de 2018 a janeiro de 2019, e à Coordenação de Aperfeiçoamento de Pessoal do Ensino Superior (CAPES) pela bolsa CAPES-PRINT de abril de 2019 a julho de 2019, que possibilitaram sua permanência, nesse período, como Professeur Invité no Observatoire Sociologique du Changement-Sciences Po, Paris.

${ }^{2}$ Outra reforma de grande impacto no Brasil ocorreu em 1966, sob a ditadura militar-civil, permitindo ao trabalhador "optar" entre o regime de estabilidade no emprego depois de 10 anos na mesma empresa, e o Fundo de Garantia por Tempo de Serviço, instituído pela Lei 5.107, de 13/09/1966, que entrou em vigor em janeiro de 1967. Na prática a estabilidade foi extinta, e alguns estudos mostra-
}

Congresso brasileiro aprovou e o presidente Michel Temer sancionou a lei que permite a terceirização sem restrições em todos os setores econômicos (Brasil, 2017). Em julho, foi a vez da Reforma Trabalhista, aprovada e sancionada para entrar em vigor em novembro. ${ }^{3}$ Na França, os cortes foram menos drásticos, porém as medidas tomadas em setembro de 2017 pelo presidente Emmanuel Macron, por meio de um conjunto de ordonnances (atos presidenciais com força de lei), estão sendo vividas como um ataque importante ao Código do Trabalho, aprofundando mudanças já presentes desde 2016, sob o governo do socialista François Hollande, as quais seguiam tendência iniciada há alguns anos.

As mudanças afetam dimensões centrais das relações de trabalho. A lei da terceirização brasileira abriu as portas para contratos com baixa proteção legal, e a Reforma introduziu ram que a rotatividade de mão de obra aumentou muito com a nova lei (por exemplo, Macedo; Chahad, 1985). Mudanças abrangentes voltariam a ocorrer em 1967, dentre outras coisas revendo as normas da negociação coletiva. Ver Silva (2008).

${ }^{3}$ A reforma (Lei 13.467/2017) foi votada pela Câmara em abril e pelo Senado em 11 de julho, sendo sancionada pelo presidente Michel Temer dois dias depois, para entrar em vigor em novembro de 2017. 
modalidades ainda mais precárias de contratação, como os contratos intermitentes, parciais, autônomos e outros; flexibilizou a jornada de trabalho, permitindo o emprego de jornadas de 12 por 36 horas em todos os setores da economia, redução de intervalos para almoço, negociação das férias, redução do tempo computado como horas extras etc.; permitiu a redução da remuneração, com possibilidade de o trabalhador receber menos do que o salário mínimo, com introdução de remuneração por hora, por produtividade, por gorjetas etc.; flexibilizou normas de saúde e segurança no trabalho, incluindo trabalho insalubre da mulher gestante; fragilizou os sindicatos, com mudanças na forma de financiamento das entidades e redução de seu papel de intermediário nas relações contratuais entre patrões e empregados; impôs sérios obstáculos ao acesso à Justiça do Trabalho por parte dos trabalhadores, como o fim do princípio da gratuidade da justiça, dentre outras medidas. ${ }^{4} \mathrm{Na}$ França as reformas adotadas a partir de 2016 reduziram custos de demissão, facilitaram demissões coletivas em caso de dificuldades econômicas e simplificaram os mecanismos de negociação das relações de trabalho internas às empresas, em especial a jornada de trabalho. Sabemos que esse tema, em particular, é indicador muito sensível de mudanças no mundo do trabalho (Dal Rosso, 1997; Miné, خे 2017a). Pois a Loi Travail de $2016,{ }^{5}$ ou Lei El Khomri, nome da ministra do Trabalho de Franสิ çois Hollande, transferiu para o âmbito da em-

ธิ ${ }^{4}$ Análise sistemática da nova lei em Teixeira e colaboradores (2017). Ver também Carelli Lacerda e Casagrande (2018).

${ }^{5}$ Lei n ${ }^{\circ} 2016-1088$ de 8 de agosto de 2016 sobre trabalho, - modernização do diálogo social e fixação dos percursos profissionais. A lei dá prioridade ao acordo de empresa

ઉ sobre o acordo setorial em matéria de jornada de trabalho e

férias. Os signatários de acordos setoriais já não têm poder para fazer com que as disposições acordadas neste âmbito constituam um piso que acordos por empresa precisem obedecer (Cf. Miné, 2017b) e, em certa medida, a lei no ordenamento das relações contratuais. Até então prevalecia o que fosse mais vantajoso para o trabalhador. ${ }^{6}$

Entre os objetivos dos reformadores de ambos os países, encontravam-se: a redução da insegurança jurídica dos contratos de trabalho, com restrição do acesso dos trabalhadores à Justiça do Trabalho no Brasil e aos Conselhos Prud'hommes na França; ${ }^{7}$ a redução dos custos de demissão e contratação, dando maior flexibilidade ao mercado de trabalho; a "modernização" das relações de trabalho, adequando a legislação à nova realidade da economia (o que quer que isso queira dizer); a geração de empregos; e, no caso do Brasil, a redução da informalidade. ${ }^{8}$ Na França, foram importantes também as recomendações da União Europeia (UE) para que a legislação do país se adequasse às metas definidas por Bruxelas (Miné, 2017a). ${ }^{9}$

As reformas se enquadram na tendência mundial de recrudescimento da individualização das formas de inserção no trabalho, em detrimento das formas coletivas. Não deixa de ser paradoxal que isso ocorra de par com a celebração do coletivo, do trabalho em equipe, da cooperação no âmbito das organizações. E elas colocam novos e importantes desafios ao ${ }^{6}$ O Código do Trabalho francês prevê que, em caso de litígio a respeito da aplicação de duas normas (lei ou contrato), vale a que for mais benéfica para o trabalhador. Porém, a partir dos anos 1980, a derrogação da lei se tornou possível em alguns casos, mesmo quando prejudicial para o assalariado. Com a reforma atual, os acordos coletivos (por empresa) têm, na maioria dos casos, prioridade sobre as convenções coletivas (setoriais). Contudo, não têm prevalência sobre a lei, exceto em certos casos delimitados pela própria lei.

${ }^{7} \mathrm{O}$ objetivo parece ter sido atingido. Um primeiro balanço da queda na demanda aos Conselhos na França é Rey (2018). No caso brasileiro, a queda foi mapeada por Rinaldi e Silva (2018).

${ }^{8} \mathrm{O}$ inteiro teor da tramitação do projeto na Câmara Federal brasileira pode ser lido em https://www.camara.leg.br/proposicoesWeb/fichadetramitacao?idProposicao $=2122076$.

${ }^{9}$ As aspas destacam o fato de que as orientações "foram decididas pelo Conselho da União, composto pelos dirigentes dos Estados membros da UE. Por isso, as reformas, que parecem impostas do 'exterior', são na realidade fruto da vontade dos Estados membros, em todo o caso da maioria dos governos desses Estados" (Miné, 2017a, p. 31). As recomendações, feitas em maio de 2015, incluíam a consolidacão das medidas de redução do custo do trabalho; melhoria do acesso ao mercado de trabalho pelos candidatos a um emprego, principalmente os trabalhadores menos qualificados e os imigrantes; aumento do salário mínimo compatível com a criação de empregos e a competitividade; redução e simplificação dos encargos trabalhistas (Cf. Quatremer, 2016). 
movimento sindical, que tem seu poder contestado e enfraquecido, sendo obrigado a testar novas formas de atuação para se revitalizar (IRES, 2017; Trade, 2017) e, no caso do Brasil, tentar sobreviver depois do fim do imposto sindical (Teixeira et al., 2017).

Nos dois países, conquanto sejam ataques frontais ao arcabouço normativo vigente até então, com importante rebaixamento da proteção do trabalhador, tanto individual quanto coletivamente, as medidas abriram aos cientistas sociais oportunidade rara. Elas estabeleceram um corte temporal inconteste, transformando o mercado de trabalho num "laboratório" no qual será possível, em tese, isolar os efeitos das novas regras sobre sua dinâmica e funcionamento. Temos, em tese, um "antes" e um "depois" das reformas.

Dizemos "em tese" porque, tanto no Brasil quanto na França, modelos de relações de trabalho nos quais a legislação trabalhista é um dos principais "espaços normativos", ${ }^{10}$ é sempre lenta a adesão dos agentes econômicos a leis que afetam a distribuição da riqueza, sobretudo entre os empresários. Isso porque o processo legislativo, não raro, produz leis carentes de coerência interna. Outras apresentam elementos que podem ser arguidos quanto à sua constitucionalidade. A aplicação da nova lei trabalhista, que retira, restringe ou muda os direitos dos trabalhadores antes contidos na Consolidação das Leis do Trabalho (CLT) brasileira, ou no Código do Trabalho francês, pode resultar em recursos judiciais a instâncias superiores, que podem chegar, e amiúde chegam, no caso do Brasil, ao Supremo Tribunal Federal (STF) e, no caso da França, ao Tribunal de Recursos (Cour d'Appel) quando o litígio for de menos de $€ 4.000$, ou ao Tribunal de Segunda Instância (Cour de Cassation), se for superior àquela soma. E uma sentença contrária aos interesses do empregador, proferida anos depois de impetrada a ação, pode resultar em perdas

${ }^{10}$ A referência aqui é Noronha (2000), para quem haveria três principais espaços normativos das relações de trabalho: a lei; os acordos e contratos coletivos; a discrição das empresas. monetárias de monta, incluindo multas, juros e correção monetária sobre valores devidos. Ademais, tramitam no STF várias Ações Diretas de Inconstitucionalidade (ADI) contra dispositivos importantes da nova lei brasileira. ${ }^{11}$ Em face disso, os empresários costumam esperar por decisões judiciais que consolidem a interpretação dos tribunais sobre as novas regras, evitando incorrer em custos futuros. É o grau de incerteza sobre se a legislação vai "pegar" ou não que determina o ritmo de sua adoção pelo agente econômico mais forte nas relações de trabalho, o empregador.

Por fim, dizemos "em tese" porque a legislação não é a única variável a ditar o funcionamento dos mercados de trabalho. São importantes o nível da atividade econômica, as taxas de investimentos públicos e privados, o nível de qualificação da força de trabalho, a estrutura da oferta de empregos, a taxa de salários etc. Ainda assim, como as reformas foram intensas nos dois países, e muito concentradas no tempo, devemos ser capazes de detectar mudanças na dinâmica dos mercados de trabalho, permitindo identificar um "antes" e um “depois” de sua implantação.

Passado um ano e meio ou mais da vigência das novas regras nos dois países, já podemos detectar impactos relevantes na dinâmica dos mercados de trabalho? Se sim, até que ponto elas vêm cumprindo suas promessas (gerar empregos, reduzir a informalidade etc.)? Neste artigo, centraremos nossa atenção nas populações mais vulneráveis dos dois países. O que aconteceu com as taxas de desemprego após as reformas? E com as formas contratuais mais vulneráveis e inseguras (informalidade no Brasil, contratos de duração determinada, contratos de ínterim na França)?

${ }^{11}$ É o caso da ADI 5829, na qual a Federação Nacional dos Trabalhadores em Empresas de Telecomunicações e Operadores de Mesas Telefônicas contesta a constitucionalidade de vários aspectos da legislação, como o trabalho intermitente, a possibilidade de remuneração inferior ao salário mínimo, a jornada de 12 horas e outros (Cf. Nova..., 2017). Há outras ADIs tramitando no STF. 


\section{O PROBLEMA}

A literatura sobre impactos das mudanças de legislação sobre as dinâmicas dos mercados de trabalho é extensa. ${ }^{12}$ Mais comum entre os economistas, não está fora dos horizontes da sociologia econômica e do trabalho. Proporção não desprezível dos países ocidentais vem revendo seu arcabouço normativo de proteção das populações que vivem de seu trabalho, e a literatura tem chamado a atenção para o aumento da vulnerabilidade social em múltiplas dimensões da vida dessas populações. Termos como "precarização" (Appay, 2005; Druck, 2011), "vulnerabilidade", "precariado" (Braga, 2017; Castel, 2011; Paugam, 2009; Standing, 2011) e “precariedade” (Cingolani, 2017; Paugam, 2000) povoam as análises sobre as mudanças nas relações de emprego e trabalho em todo o mundo.

Mas os mercados de trabalho não são uniformes. O próprio fato de utilizarmos "mercados" no plural já o denota. Tomando-se apenas o caso francês, registram-se mais de quarenta tipos diferentes de contratos de trabalho, incluindo contratos "formais", contratos por tempo parcial, interinos, de aprendizagem, contratos com ajuda do Estado (contrats aidés) etc. Essas formas contratuais começaram a surgir e a ser registradas pela literatura já no final تُ dos anos 1970, ganhando corpo nos anos 1980, స agora sob o rótulo da "flexibilidade". Não me$\dot{8}$ nos que três importantes livros publicados na França (Boyer, 1987; Guitton; Maruani; Reynaud, 1991; Maruani; Reynaud; Romani, 1989) enfocaram esse tema, considerado então incontornável para se entender a evolução dos $\dot{2}$

ceito construído em contraste com uma forma

"típica" de emprego, que alguns nomearam de "norma fordista" (Tripier, 1998). Em qualquer caso, tentava-se apreender a precarização, ou

balanço da literatura econômica está em Bensusán (2006).

${ }^{13}$ Importante estudo para a América Latina é De la Garza (1997) a perda de direitos e de segurança socioeconômica por parte de populações antes protegidas pela universalização do assalariamento. ${ }^{14}$

Na França, aquela norma teve, historicamente, o rosto do Contrat à durée indéterminée (Contrato de Duração Indeterminada - CDI), sendo o resto considerado como precário, enquanto, no Brasil, o mais perto que se chegou da norma foram os contratos assalariados "com carteira assinada", além dos contratos dos servidores públicos. Mas a "norma" brasileira nunca se universalizou, como foi o caso dos CDI franceses, o que torna impróprio usar "precarização" ou "precariedade" no mesmo sentido que no caso francês, como apontam Bouffartigue e Busso (2009). ${ }^{15}$ Os mercados de trabalho brasileiros sempre foram muito precários, a precariedade sendo mais ou menos intensa para homens ou mulheres, jovens ou velhos, servidores públicos ou empregados no setor privado, brancos ou não brancos etc.

Porém, e como argumenta Castel (2011, p. 21), mesmo que a forma CDI ainda prevaleça na França, o "precariado" (neologismo misto de precariedade e proletariado) já não pode ser considerado marginal, pois qualifica um "permanente" e "novo modo de regulação do mercado de trabalho". Para o autor, ele configura uma nova condição infrassalarial, que se estabelece aquém do emprego clássico e de suas garantias, por não assegurar mais a independência econômica e social dos trabalhadores. Ora, essa realidade já era típica do Brasil, historicamente marcado pela insegurança socioeconômica dos que vivem de seu trabalho. Isso quer dizer que as mudanças em curso, já de longa data, tendem a aproximar a realidade dos dois países. ${ }^{16}$

14 Appay (2005) argumenta que a "precarização", no que ela qualifica de "social”, é portadora de mudanças sociais, tendo por isso uma dimensão política.

15 No Brasil, a informalidade acolheu entre 35\% e 55\% dos ocupados desde a criação da Carteira de Trabalho em 1932. Ver Cardoso (2019).

16 Vai nessa direção o trabalho de Bouffartigue e Busso (2009), que compara França e Argentina e tece um paralelo entre os conceitos de "precariedade", que descreveria as mudanças no mundo do trabalho dos países do Norte, e "informalidade", referida aos países do Sul. Eles insistem no fato de que não se trata de sinônimos, porém de conceitos que recobrem fenômenos em certa medida semelhan- 
Em ambos os casos a norma negociada tende a reger a relação de trabalho, deslocando - mas não derrogando inteiramente - a norma legal, o que reflete importante recuo do Estado nessa matéria (Légé, 2019). E, ainda que seja controverso, ao menos no caso francês, estarmos diante de uma inversão da hierarquia das normas, levando a rever o que historicamente caracterizou o país - a lei prevalecia sobre o contrato setorial, que prevalecia sobre o contrato por empresa, valendo o que fosse mais favorável ao trabalhador -, parece incontroverso que "o conteúdo substancial do direito está sendo deslocado da norma legal para a norma convencional e, principalmente agora, para o acordo de empresa” (Miné, 2017b). ${ }^{17}$ No Brasil, não há controvérsia quanto ao tema. A reforma de 2017 visou a dar prevalência ao negociado sobre o legislado, embora não estabeleça que acordos por empresa possam derrogar as convenções coletivas por categoria.

Diante disso, como se comportam os indicadores de precariedade e vulnerabilidade nos mercados de trabalho do Brasil e da França? Até que ponto as mudanças de fato aproximam os destinos de brasileiros e franceses, em termos de aumento da insegurança socioeconômica, tal que permita, ao menos, empregar "precariedade" no mesmo sentido nos dois casos?

É preciso ter em mente que as reformas podem ainda não ter afetado os mercados de trabalho, por serem recentes e ainda estarem sendo

tes, a principal diferença estando referida à natureza dos Estados de Bem Estar nos dois países.

${ }^{17}$ Para Michel Miné (2017b), a lei continua a organizar a articulação das fontes entre si (de acordo com o artigo 34 da Constituição francesa). Assim, cabe à lei decidir quando (e em quais casos) o acordo de empresa prevalece ou não sobre o acordo setorial, quando a lei prevalece sobre os acordos, quando a lei é supletiva etc. Portanto, isso não caracterizaria uma "inversão" da hierarquia das normas (pois não é um acordo coletivo que organiza a articulação das normas). Tampouco estamos num sistema onde os acordos não estariam mais enquadrados pela lei. Contudo, para alguns assuntos, é o acordo coletivo e, amiúde, o acordo de empresa que fixa a regra a ser aplicada. Assim, o conteúdo substancial da regra pode ser fixado pelo acordo, notadamente o acordo de empresa, porém respeitando da lei, que autoriza o acordo a definir a regra aplicável. Por exemplo, 1) a lei diz que as horas extras são pagas a mais (porém, não diz quanto); 2) a lei autoriza o acordo a determinar o valor a ser pago (com um teto em 10\%); 3) se o acordo não estipula nada, a lei fixa o valor acima da hora normal ( $25 \%$ ou $50 \%$ ). Agradecemos os esclarecimentos de Michel Miné. “testadas" pelos empregadores. O estudo, nesse sentido, tem caráter exploratório, embora seja sistemático e rigoroso nessa exploração. ${ }^{18}$

\section{BRASIL}

Desde 1999, e muito particularmente no período de 2003 a 2013, o Brasil viveu importante processo de redução da taxa de informalidade, uma das principais medidas de precariedade das populações que vivem de seu trabalho. Neste estudo, consideramos informais os ocupados por conta própria que não contribuíam para a Previdência Social; os assalariados sem carteira; os empregadores com apenas um empregado e que não contribuíam para a Previdência; e os trabalhadores não remunerados. ${ }^{19}$

A queda foi de 8,7 pontos percentuais entre 1999 e 2013. Até 2007, a queda relativa decorreu do fato de que foram criados mais empregos formais do que informais a cada ano, de sorte que, mesmo com o número absoluto de ocupados informalmente tendo aumentado, sua participação relativa decresceu. A partir de 2007, houve queda também absoluta, com saída de número expressivo de pessoas da condição de informalidade. Como é mostrado em Cardoso (2016a), foram mais de 2 milhões de pessoas, em sua maioria trabalhadores por conta própria, que passaram a contribuir para a Previdência Social, na esteira de programas governamentais como o Microempreendedor Individual (MEI) e o Super Simples. ${ }^{20}$ Trata-se, pois, de redução da precariedade, algo já detectado por Leite (2014). Contudo, em 2014, a taxa de informalidade não apenas parou de

${ }^{18}$ Ainda que exploratório, propomos um olhar inovador sobre os dois mercados de trabalho, ao comparar bases de dados até aqui "virgens" de comparação, a Enquête emploi em continu e a PNAD Contínua.

19 Em relação às medidas propostas por Cacciamali (1982), ou nos artigos em Oliveira e Targino (2011), incluímos, entre os informais, os empregadores com apenas um empregado e que não contribuíam para a previdência, seguindo Cardoso (2016a). As condições de vida e trabalho desses ocupados são muito semelhantes às dos trabalhadores por conta própria não contribuintes para a previdência.

${ }^{20}$ Para um estudo econométrico rigoroso sobre esse processo, ver Rocha, Ulyssea e Rachter (2018). 
cair, como subiu levemente, tanto no caso dos homens quanto das mulheres, e novamente em 2015 (Gráfico 1).

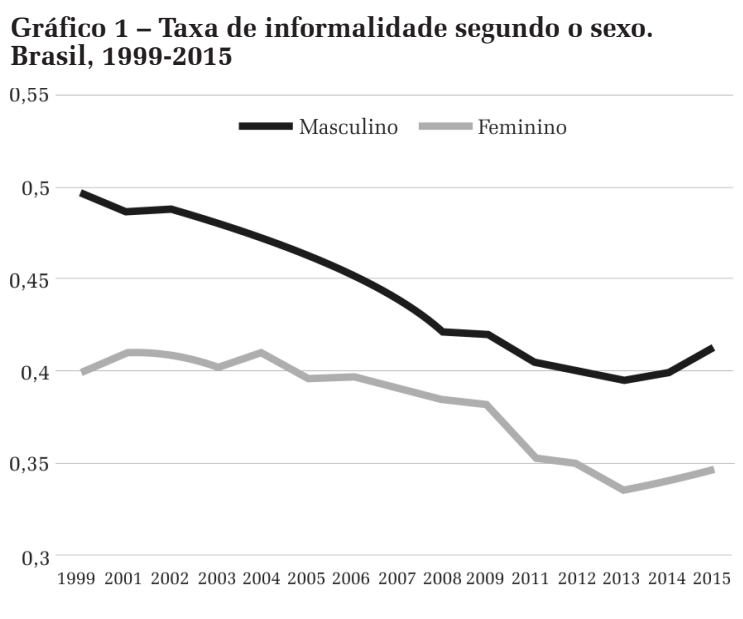

Fonte: Elaborado pelos autores, com base nas PNADs 1999 a 2015.

Note-se, pelo mesmo Gráfico 1, que as taxas para os sexos distavam 10 pontos percentuais no início do período (1999), tendo convergido lentamente até 2009 em razão da queda mais acentuada entre os homens, divergindo novamente nos anos seguintes em função da aceleração do ritmo de queda entre as mulheres. Isso sugere que elas aderiram mais intensamente às políticas de redução da informalidade do que eles, por meio da adesão mais ativa às políticas governamentais lançadas, o justamente, a partir de 2009 (Rocha; Ulyssea; స్ Rachter, 2018). Quando a informalidade co$\therefore$ meçou a crescer novamente depois de 2013, a diferença entre homens e mulheres manteve-se em torno de 6 pontos percentuais, segundo essa base de dados.

Contudo, outra base de dados igualmente oficial, a PNAD Contínua (PNADC), cuja coleta teve início em 2012, apresenta figuras bastante distintas da PNAD tradicional. Ambas são pesquisas por amostra de domicílios, mas as diferenças na metodologia de coleta e na amostragem impedem que utilizemos a PNADC para completar a série histórica da PNAD. ${ }^{21}$ Isso fica evidente na análise da informalidade.

${ }^{21}$ Para a diferença entre as duas pesquisas, ver IBGE (2014).
Na versão "anual" da PNADC,22 a taxa de informalidade é maior entre as mulheres, e a diferença entre os sexos é muito menor. Se, na PNAD antiga, chegava a 6 pontos percentuais em favor dos homens em 2015, na nova metodologia, a diferença não chegou a 2 pontos naquele ano, com as mulheres na frente. Além disso, enquanto na pesquisa mais antiga a informalidade parou de decrescer em 2013, aumentando daí por diante, na PNADC a queda é estancada apenas em 2014, permanecendo estável em 2015 e revertendo-se de 2016 em diante. Ademais, a partir de 2016, a diferença entre homens e mulheres não é significativa em termos estatísticos, estando abaixo de um ponto percentual (Gráfico 2). Seja como for, a tendência de aumento da informalidade depois de 2015 é clara (para as mulheres cresce a partir de 2016), ainda que tenha ocorrido em intervalos temporais distintos nas duas pesquisas do IBGE. E ela afetou ambos os sexos igualmente, sendo que, na PNADC, não vemos diferenças importantes entre eles.

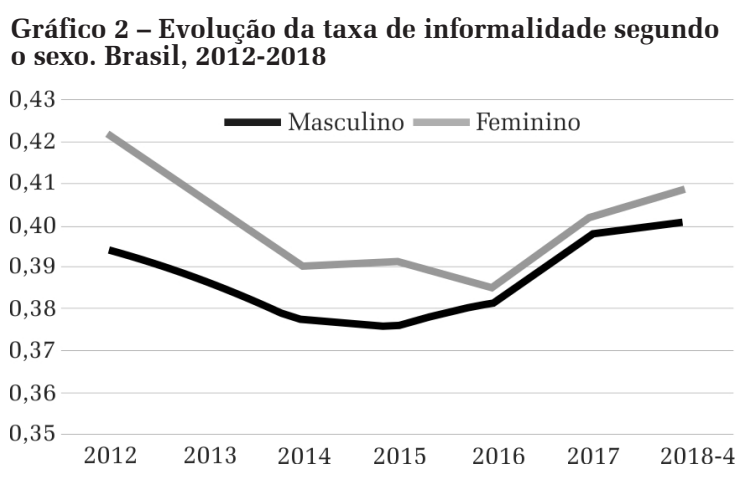

Fonte: Elaborado pelos autores, com base nos microdados da PNAD Contínua Anual 2012 a 2017, e da PNAD Contínua 2018-4.

${ }^{22}$ A PNADC vai a campo todos os meses, e produz arquivos trimestrais de microdados que consolidam as amostras dos trimestres. Cada domicílio é visitado uma vez por trimestre ao longo de cinco trimestres, de modo que temos informação sobre seus moradores por todo esse período. O IBGE utiliza uma das "visitas" a esses domicílios para gerar a PNAD Anual, que aplica um questionário mais extenso, semelhante à PNAD antiga. Entre 2012 e 2015, a visita utilizada foi a primeira, mas em 2016 e 2017, foram aplicados módulos específicos na primeira e na quinta visitas. Utilizamos aqui apenas a primeira visita de cada um dos anos, para efeito de comparabilidade. A PNAD antiga visitava em torno de 140 mil domicílios em 1.100 municípios, enquanto a PNADC visita 211 mil domicílios em cerca de 3 mil municípios, mais da metade dos existentes no Brasil. Tem, portanto, maior cobertura, principalmente nos municípios menores. 
Por esses dados vemos que a crise econômica de 2015 e 2016, que resultou na queda de $3,8 \%$ no PIB no primeiro ano e de $3,6 \%$ no segundo, demorou a ser sentida pelo mercado de trabalho no que respeita à taxa de informalidade. ${ }^{23}$ Apenas em 2016 vemos crescimento no caso dos homens, ainda assim modesto. É em 2017, já no âmbito da diminuta recuperação econômica (crescimento de $1 \%$ do PIB), que o aumento é mais pronunciado, e novamente em 2018, passado mais de um ano de vigência da reforma. Nesse ano, a taxa era 2 pontos percentuais mais alta do que em 2016 para ambos os sexos. Desse ponto de vista, uma das promessas da nova legislação trabalhista, de reduzir a informalidade, não parece ter ocorrido. A (leve) retomada da economia, em lugar de melhorar, tornou mais precário o perfil ocupacional do mercado de trabalho no que respeita à taxa de informalidade.

A taxa de desemprego teve comportamento levemente distinto. ${ }^{24}$ Como mostra o Gráfico 3, ela era de 6\% para os homens e de 9\% para as mulheres em 2012, tendo diminuído um pouco em 2014, para então subir intensamente entre 2015 e 2017, atingindo mais de $14 \%$ no caso delas e quase $11 \%$ no caso dos homens, crescimento de cinco pontos percentuais nos dois casos, portanto. A recessão impactou fortemente as chances de se encontrar um emprego, e o pequeno crescimento econômico de 2017 não inverteu a tendência. Isso só ocorreu em 2018, quando a taxa, no último trimestre daquele ano, ficou abaixo de $14 \%$ para elas e em $10 \%$ para eles. A queda foi de menos de 1 ponto percentual. Contudo, ela não pode ser atribuída à reforma trabalhista, já que, no caso dos homens, resultou da diminuição na taxa de participação na População Economicamente Ativa (PEA) de 0,7 ponto percentual, e do aumento do desalento, de 0,3 ponto

${ }^{23}$ As taxas de crescimento econômico foram extraídas do IPEADATA.

${ }^{24}$ Também neste caso, não há comparação entre a PNAD antiga e a Contínua. A metodologia de mensuração do desemprego mudou substancialmente, não fazendo sentido apresentar a série histórica desde 1999. percentual. E, no caso das mulheres, a queda é quase inteiramente explicada pelo aumento do desalento (0,2 ponto percentual - pp.) e da participação em ocupações informais (0,4 pp.).

Gráfico 3 - Taxa de desemprego segundo o sexo. Brasil, 2012-2018

0,16

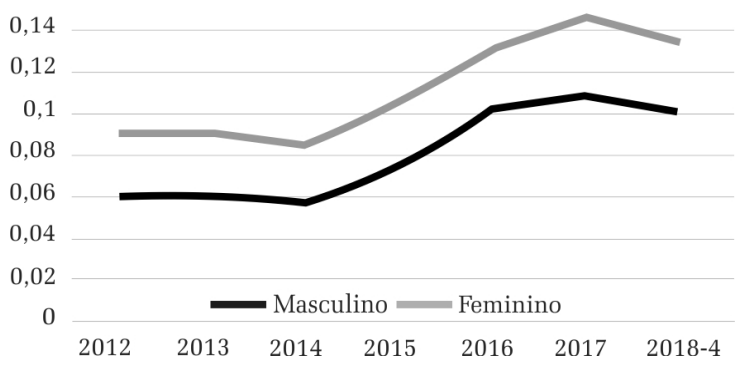

Fonte: Elaborado pelos autores, com base nos microdados da PNAD Contínua Anual 2012 a 2017, e da PNAD Contínua 2018-4.

Embora a PNADC não seja comparável com a PNAD antiga, ela apresenta vantagens importantes, que, além de permitir análises de novo tipo, a tornam comparável com a Enquête emploi en continu francesa. No desenho amostral da PNADC os domicílios são visitados, num esquema de rotação, durante cinco trimestres consecutivos. Com isso, se as mesmas pessoas continuarem morando no mesmo domicílio, é possível acompanhá-las ao longo desse período. Entre o primeiro trimestre de 2012 e o quarto trimestre de 2018, a correspondência entre a primeira e a quinta visita a cada domicílio foi sempre superior a $60 \%$, isto é, mais de $60 \%$ das pessoas presentes na primeira visita continuavam presentes na quinta. ${ }^{25}$ Isso representava uma amostra nacional entre 70 mil e 75 mil indivíduos por painel emparelhado de um ano para outro. ${ }^{26}$

${ }^{25}$ A antiga Pesquisa Mensal de Emprego (PME), que foi substituída pela PNADC, também utilizava um esquema de rotação que permitia comparar o mesmo domicílio em dois pontos no tempo. Contudo a pesquisa era restrita a 6 regióes metropolitanas, e a correspondência era, em geral, inferior a $40 \%$. A PME como painel foi muito pouco analisada no Brasil. Ver os trabalhos pioneiros de Pero (1995) e Amadeo e Pero (2000), além de Cardoso (2016b).

${ }^{26}$ Para este estudo, o primeiro trimestre de um ano foi emparelhado com o primeiro trimestre do ano seguinte, o segundo trimestre com o correspondente do ano seguinte, e assim por diante. O problema com esse tipo de painel é que as pessoas que permanecem no mesmo domicílio de um ano a outro não têm, em média, o mesmo perfil das que saem. Essas são, em geral, mais jovens, homens e mulheres que vão constituir família ou estudar. Tendem 
Nosso interesse em relação a essa base de dados específica foi identificar eventuais mudanças na probabilidade de destino no mercado de trabalho de um ano a outro, a partir de 2012, de homens e mulheres em diferentes posições na ocupação e condição de atividade. As perguntas a serem respondidas incluíam: a reforma trabalhista alterou as chances de destino ocupacional das pessoas? Ou, formulando de outra maneira: a dinâmica de inserção econômica de homens e mulheres mudou depois da reforma? Essa mudança, se houve, ocorreu na direção "prometida" pelos reformadores, isto é, melhorando as condições de inserção? Ou terá aumentado a precariedade?

Iniciemos pelo desemprego. O Gráfico 4 mostra o que ocorreu com as chances de um desempregado, num ano, estar ocupado no ano seguinte. A informação toma por base a média dos quatro trimestres do ano t1 e a média dos quatro trimestres do ano t2. No caso dos homens, a chance de se estar ocupado no ano $\mathrm{t} 2$ estando desempregado em t1 ficou estável e próxima de $58 \%$ nos dois primeiros biênios (2012-2013, 2013-2014). A estabilidade também marcou as trajetórias das mulheres nesses biênios, porém a uma taxa bem mais baixa, em torno de $42 \%$. Contudo, já no biênio 2014-2015, as chances de reinserção dos $\vec{\sim}$ desempregados em $\mathrm{t} 2$ começam a cair acentuจ. adamente. No primeiro ano da recessão (2015), são quase 3 pontos percentuais de queda. Um desempregado, em 2014, tinha 55\% de chance de estar ocupado em 2015, proporção que caiu a $49 \%$ em 2015-16 e a menos de $48 \%$ nos dois biênios seguintes, que observaram leve - recuperação econômica, como vimos. No caso das mulheres, saiu-se de $42 \%$ no primeiro biêले nio para 35\% no biênio 2016-2017. No último $\overrightarrow{>}$

ธิ a permanecer os membros do núcleo familiar, quando ele existe. E a maioria dos casos de não emparelhamento de um ano a outro (60\% ou mais dependendo do ano) deve-se a त famílias que se mudaram para outro domicílio, ou cuja en-

- trevista não foi realizada por ausência dos membros. Aqui

I também a probabilidade de mudar de domicílio é maior en-

U tre famílias mais jovens, de homens e mulheres entre 23 e

35 anos, segundo a mesma base de dados. Logo, a amostra é

enviesada para coortes um pouco mais velhas, já que os que

permanecem nos domicílios de um ano para o outro têm 3,6 anos a mais de idade, em média, do que os que saem. biênio (2017-2018), houve leve recuperação, de 1,6 ponto percentual. Ou seja, a chance de reinserção ocupacional dos desempregados caiu 11 pontos percentuais no caso dos homens, durante a recessão, perda não revertida nos dois anos de retomada do crescimento, menos ainda no primeiro ano de vigência da reforma trabalhista. No caso das mulheres, a queda foi de 7 pontos percentuais, estancada em 2018 com leve aumento na chance de reinserção. Contudo 63\% das desempregadas em 2017, que estavam ocupadas em 2018, tinham uma ocupação informal, sobretudo no emprego doméstico. A taxa tinha sido de 53,8\% no biênio 2012-2013. Logo, o pequeno aumento na chance de estar ocupada de um ano a outro se deu, em sua maioria, na direção da informalidade, não de ocupações regidas pela nova legislação trabalhista. Se um dos motes da reforma, ao reduzir direitos trabalhistas, foi permitir a reinserção em ocupações com direitos, ainda que mais precárias, isso não ocorreu.

Gráfico 4 - Probabilidade de homens e mulheres desempregados no ano t1 estarem ocupados no ano t2. Brasil, 2012-13 a 2017-2018

0,65

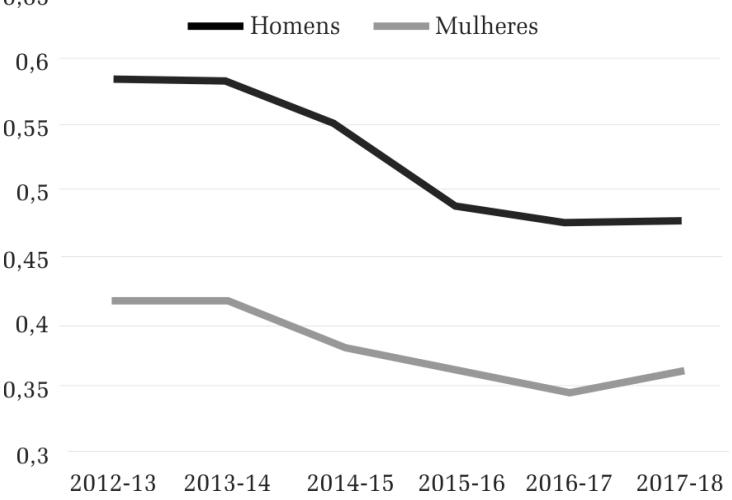

Fonte: Elaborado pelos autores, com base nos microdados da PNAD Contínua de 2012 a 2018.

O Gráfico 5 ilustra a evolução temporal da probabilidade de homens e mulheres ocupados informalmente no ano t1, estarem ocupados formalmente em $t 2$. As curvas têm desenho semelhante às do gráfico anterior, com as chances dos homens sendo mais altas do que as das mulheres, apresentando estabilidade nos dois primeiros biênios (em torno de 17\% 
para os homens e de $12 \%$ para as mulheres) e caindo durante os anos recessivos e também em 2017, no caso dos homens. A reversão da curva em 2017-18 é muito suave, de menos de 0,4 ponto percentual no caso delas e de 0,3 ponto no caso deles. E ela ocorreu num mercado de trabalho no qual a taxa de informalidade aumentou levemente, como vimos. Esse é o único indicador que poderia estar relacionado com novas regras de contratação. Isso porque $45 \%$ desses poucos casos de transição de uma ocupação informal para uma formal decorreram, provavelmente, da formalização do vínculo anterior pelo mesmo empregador, já que essas pessoas estavam exatamente na mesma ocupação do ano anterior, segundo a mesma fonte de dados. Se for o caso de o empregador se ter sentido atraído pelas novas regras, a ponto de formalizar o vínculo de seu empregado, estamos falando de menos de 0,2 ponto percentual, no caso das mulheres, e em torno de 0,1 ponto no caso dos homens, ou $45 \%$ do pequeno crescimento na taxa de migração informal-formal.

Gráfico 5 - Probabilidade de homens e mulheres ocupados informalmente no ano t1estarem ocupados formalmente em t2. Brasil, 2012-13 a 2017-2018

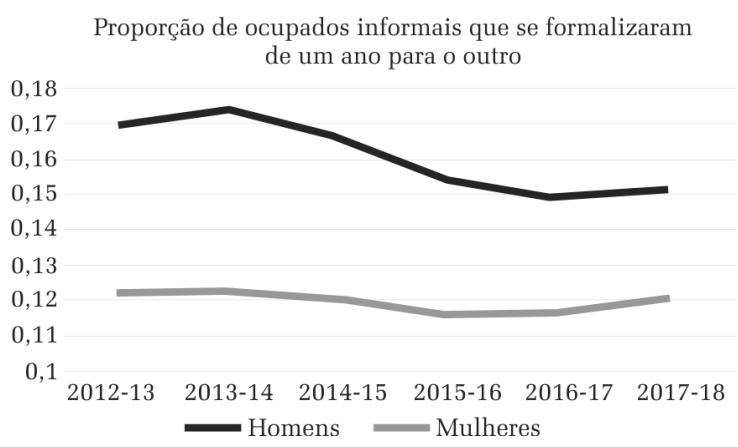

Fonte: Elaborado pelos autores, com base nos microdados da PNAD Contínua de 2012 a 2018

Já o Gráfico 6 mostra a probabilidade de jovens homens e mulheres de 18 a 25 anos, que não estudavam, não trabalhavam e não procuravam emprego (eram "nem nem"), no ano t1, estarem na mesma condição no ano t2. A taxa para os homens sai de $36 \%$, no biênio 2012-2013, para quase 44\% no último biênio, aumento significativo da proporção de jovens homens presos à condição "nem nem" de um ano a outro. No caso das mulheres, a proporção variou em torno da média de $62 \%$. Nem o período de crescimento do nível de emprego (dois primeiros biênios), nem a recessão econômica afetaram as chances delas, e a retomada do crescimento, em 2017, na verdade, aumentou um pouco as chances de que aquelas que estavam como "nem nem", em t1, se mantivessem assim em t2. Para ambos os sexos, pois, o ano de 2018 piorou as chances de os jovens deixarem a condição "nem nem" observada no ano anterior. ${ }^{27}$

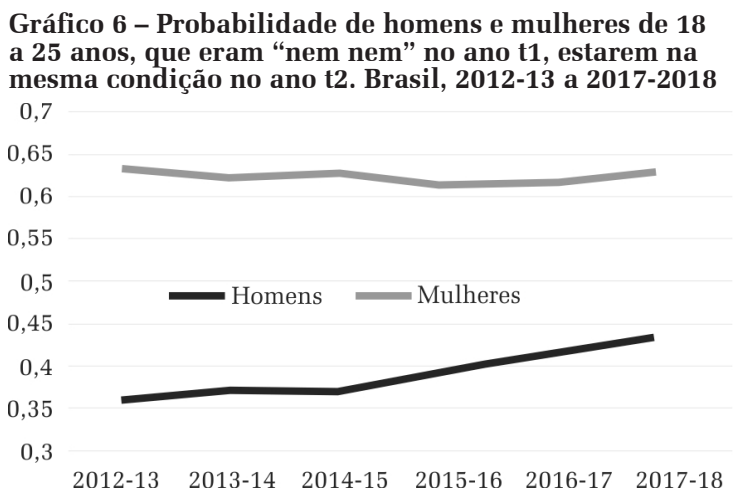

Fonte: Elaborado pelos autores, com base nos microdados da PNAD Contínua de 2012 a 2018 .

Por esses três indicadores (desemprego, informalidade e condição "nem nem”), não podemos afirmar que houve impacto relevante da reforma na melhoria das condições de inserção das pessoas no mercado de trabalho brasileiro. O desemprego continuou alto, a informalidade aumentou com a retomada do crescimento, as chances de um desempregado estar ocupado não tiveram variação significativa mesmo em meio ao (leve) crescimento econômico iniciado em 2017, e as chances de um trabalhador informal em um ano estar em melhor posição no ano seguinte tampouco variaram substancialmente, permanecendo muito baixas, tanto para homens quanto para mulheres. A reforma,

${ }^{27}$ Esse achado vai na direção contrária ao relatado por Naércio Menezes Filho em 2013. Com base na PME, que cobria seis regiões metropolitanas, ele afirmou que a condição "nem nem" era transitória para a maioria dos jovens. Isso não é verdade para as mulheres, como vemos no Gráfico 6. E, mesmo no caso dos homens, $44 \%$ de permanência na condição de um ano a outro não é desprezível (Cf. Menezes Filho, 2013). O artigo em que se baseia a afirmação de Menezes Filho não se encontra mais na página do Insper. 
na verdade, está associada com o aumento da precariedade do mercado de trabalho brasileiro.

\section{FRANÇA ${ }^{28}$}

Como já mencionamos, na França, a reforma trabalhista do governo Hollande foi aprovada em agosto de 2016, e novas e mais profundas mudanças ocorreram em 2017, no governo de Emmanuel Macron. Numa época de enfraquecimento dos sindicatos (IRES, 2017), dentre as principais mudanças em curso destacam-se o aumento do poder unilateral dos empregadores na determinação da jornada de trabalho; a limitação dos benefícios rescisórios (Prud'hommes) em caso de demissão sem justa causa (com consequente redução dos custos de demissão); e novos critérios de demissão econômica dos assalariados (Légé, 2019). Dentre tais critérios, destacam-se o Plano de Garantia ao Emprego (Plan de sauvegarde de l'emploi PSE), que permite a uma empresa de mais de 50 assalariados demitir ao menos uma dezena deles; e dois dispositivos flexibilizadores: a ruptura convencional individual e a ruptura convencional coletiva. A primeira modalidade é uma forma "amigável”29 (à l'amiable) de ruptura do contrato de trabalho, criada em 2008 (De Bony, 2019). Permite que um assalariado com CDI e seu empregador cheguem a um acordo sobre as condições da ruptura do contrato de trabalho que os vincula. A segunda modalidade, a ruptura convencional coletiva, também prevê, desde 2017, uma ruptura do contrato de trabalho a partir de um acordo entre o empre$\dot{0}$ gador e o assalariado (Cf. La rupture..., 2019). $\therefore$ Mas, diferentemente da primeira, trata-se de ले um modo de demissão coletiva que permite

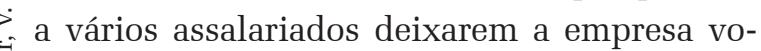
luntariamente. Ou seja, ela oferece a possibi-

${ }^{28}$ Agradecemos a Quentin Chapuis pelo apoio dado no tratamento de parte dos dados estatísticos da França.

${ }^{29}$ Ao que contrário do que o nome sugere, esses acordos são menos o resultado de conciliações "amigáveis” do que uma saída financeira e institucional de uma variedade de situações conflitivas (Berta et al., 2012 apud Quijoux, 2019, p. 67). lidade de os assalariados romperem o contrato de trabalho de maneira negociada, o que evita recorrer aos Prud'hommes. As indenizações outorgadas costumam ser inferiores ao que o requerente conseguiria na justiça trabalhista. ${ }^{30}$

Ainda não houve tempo para que essas mudanças apareçam nas estatísticas que, no momento em que escrevemos, estão disponíveis apenas até 2017, diferentemente do Brasil. Uma particularidade da França é o fato de a Enquête emploi en continu (EEC), com metodologia de rotação amostral semelhante à brasileira, ter se iniciado em 2003. ${ }^{31}$ Isso permite uma série histórica sem interrupções a partir desse ano, enquanto, no Brasil, a PNAD deixou de existir em 2015 e a PNADC, que a sucedeu, não é comparável. Além disso, não existe, no caso francês, algo que se aproxime da informalidade brasileira. Todos os ocupados, se assalariados, têm contratos formais de trabalho, seja por tempo determinado, seja indeterminado, sendo que as modalidades de exercício podem variar (ínterim, parcial etc.). Por sua vez, os trabalhadores independentes (por conta própria) também são considerados formalmente ocupados, pois têm registro empresarial e pagam impostos sobre a atividade que desempenham. Com isso, as medidas de qualidade das ocupações são necessariamente diferentes das encontradas no Brasil. ${ }^{32}$ Selecionamos alguns indicadores capazes de apreender a dinâmica do mercado de trabalho ao longo do tempo, na

${ }^{30}$ Não raro o diálogo entre o empregado e o empregador se assemelha a um tipo de aposta, em que o empregado aceita uma soma de dinheiro do empregador, em troca da rescisão do seu contrato de trabalho, mais baixa do que ele poderia receber caso recorresse aos Prud'hommes, porém sem ter a certeza, nesse caso, de ganhar a causa e de conseguir uma quantia maior.

${ }^{31}$ A partir de 2003, a Enquête emploi en continu substituiu a Enquête anual. A coleta dos dados é feita ao longo do ano e, como na PNADC (inspirada na experiência mexicana), permite avaliações trimestrais do emprego e do desemprego. A Enquête é mais precisa na mensuração da situação dos desempregados, assim como das mudanças de situação em relação ao trabalho: passagem da escolaridade à vida profissional, da atividade à aposentadoria, mudança de profissão etc. Um mesmo lar é pesquisado por seis trimestres consecutivos, com uma visita na 1a e na última entrevistas e as demais realizadas por telefone. A amostra é renovada em um sexto a cada trimestre (Cf. INSEE, 2017).

${ }^{32}$ Semelhanças e diferenças nos mercados de trabalho dos dois países foram sistematicamente analisadas por Demazière et al. (2013). 
esperança de captar, ainda que indiretamente, possíveis efeitos das reformas recentemente aprovadas ou, pelo menos, tendências observáveis nos últimos anos.

Como já dissemos, um dos indicadores mais importantes do modo de inserção laboral dos assalariados franceses é o tipo de contrato de trabalho, se por tempo determinado (Contrat à durée déterminée, ou CDD) ou indeterminado (CDI). O Gráfico 7 mostra a evolução desses dois tipos. Até 2008, a taxa de CDD variou pouco em torno da média, tanto para homens quanto para mulheres. Mas, a partir de 2009, sobretudo no caso dos homens, há uma lenta, mas nítida, ampliação da proporção de ocupados com contratos por tempo determinado. O crescimento de 2009 a 2017 foi de 1,5 ponto percentual no caso deles, o que se reflete na variação total, que também foi de 1,5 ponto percentual positivo. No caso das mulheres, o CDD começa a aumentar apenas em 2013, com variação, até 2017, de 1,2 ponto percentual.

A contrapartida desse crescimento é a queda na participação dos contratos por tempo indeterminado, com início também em 2009. Apesar de leve interrupção na tendência entre 2012 e 2014, ao final do período, a queda em relação a 2009 tinha sido de 3 pontos percentuais, para homens, mulheres e também no total. É importante notar que a queda mais intensa ocorreu ao final do período, quando o país estava crescendo com vigor um pouco maior: o crescimento do período de 2011 a 2014 foi de $4,4 \%$, contra $6,6 \%$ de 2014 a 2017 (INSEE, 2019). Isto é, os dois anos das reformas trabalhistas francesas coincidiram com queda significativa nos contratos CDI, mas a tendência já havia começado em 2009, e foi indiferente à variação no ciclo econômico. Contudo essa forma de contrato de trabalho não deixou de ser preponderante. Em média, ela ainda representa $3 / 4$ de todos os contratos de trabalho. Vale notar que o fim de um CDD dá direito a um beneficio (prime de précarité) equivalente a, no mínimo, 10\% (ou 6\% em caso de acordo coletivo a respeito) sobre o valor bruto recebi- do durante o contrato, o que não ocorre com o CDI. Isso pode estar reduzindo o ritmo de queda dos CDI, pois alguns empregadores preferem contratar via CDI (integral ou parcial) do que incorrer nos custos do fim de um contrato CDD (Service Public, [2019]).

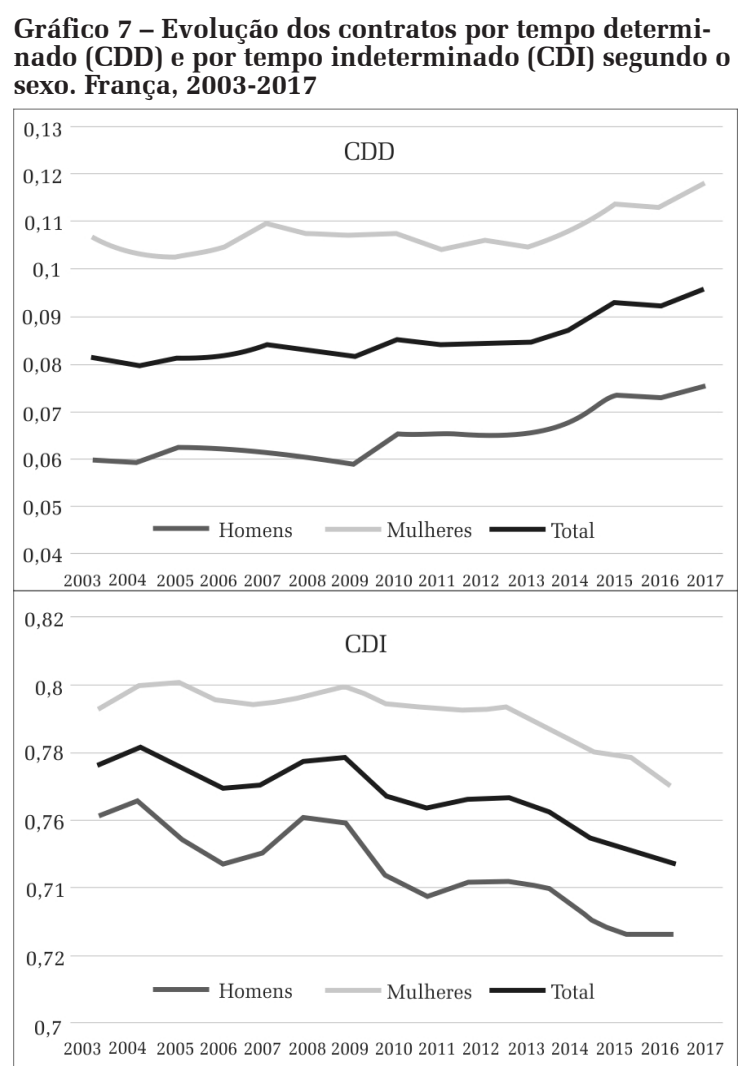

Fonte: Elaborado pelos autores, com base em Microdados da Enquête emploi en continu (2003-2017).

O desemprego é a segunda dimensão importante da vulnerabilidade e precariedade das populações que vivem de seu trabalho a ser analisada para o caso francês. O Gráfico 8 mostra a evolução da taxa de desocupação a partir de 2003. É nítido o crescimento a partir de 2008, tanto para homens quanto para mulheres. A crise financeira aproximou as taxas dos dois sexos. A diferença, que era de 2 pontos percentuais antes de 2008, passa a meio ponto percentual a partir de 2009, convergindo até que a dos homens ultrapassa a delas em 2013. A partir desse ano o desemprego das mulheres é sempre menor do que o dos homens, com pico em 2015, quando quase $11 \%$ deles esta- 
vam desempregados, contra $10 \%$ delas. Observa-se nova convergência nos anos seguintes, com queda acentuada na taxa dos homens, até que ambos os sexos apresentem níveis muito próximos e inferiores a 10\% em 2017. Contrariamente ao que se poderia imaginar, a queda não parece estar relacionada com as reformas flexibilizadoras, mas, sobretudo, com as medidas tomadas no final do governo Hollande, em janeiro de 2017, com a adoçãodo Plan 500.000 formations, que previa a qualificação profissional de desempregados e de pessoas pouco qualificadas ou sem qualificação, podendo chegar, numa etapa posterior, a 1 milhão de atendidos. ${ }^{33}$ Com isso, automaticamente, os beneficiários passaram da categoria de desempregados à de ativos. Outra parte da explicação estará relacionada com a criação de empregos numa economia que passou a crescer mais. Como a proporção de CDDs vem aumentando mesmo com o crescimento econômico, podemos estar diante de impactos da reforma trabalhista francesa, que, ao gerar novos empregos, o faz sem romper a tendência de mais longo prazo de queda nos CDIs e aumento nos CDDs.

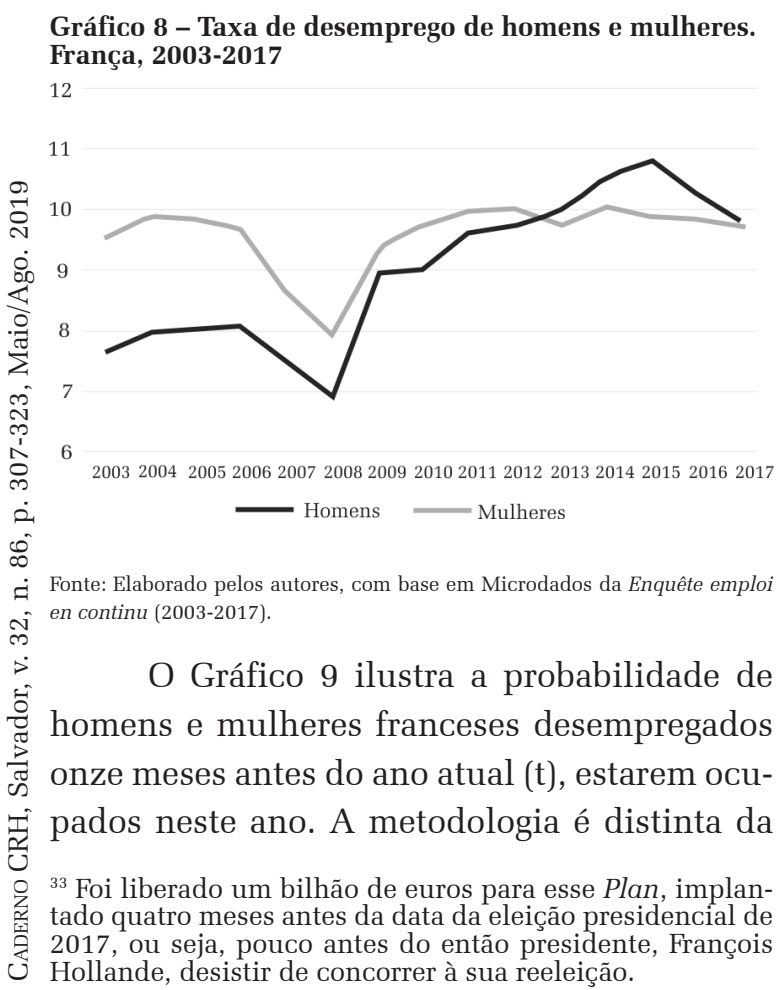

empregada na PNAD Contínua, porque a Enquête emploi oferece uma variável já emparelhada sobre a situação de ocupação ao longo de 12 meses consecutivos. Utilizamos, aqui, a informação para o primeiro trimestre de cada ano. Logo, o gráfico indica a probabilidade de alguém estar ocupado no primeiro trimestre do ano indicado, tendo estado desempregado no primeiro trimestre do ano anterior. Incluímos o quarto trimestre de 2017 porque a Enquête captou importante inflexão na tendência anterior, comentada em seguida.

Chama a atenção a semelhança das chances de homens e mulheres, com queda acentuada na probabilidade de inserção dos desempregados entre 2013 e 2016, que sai de algo próximo de $32 \%$, no caso delas, e 33,5\%, no caso deles, para cerca de $28 \%$ e $28,5 \%$ respectivamente, entre um ano e outro. O movimento é compatível com o do aumento do desemprego, sobretudo entre os homens. Isto é, no período, não apenas aumentou a proporção de desempregados, como as chances de recolocação diminuíram. Em 2017, a tendência se inverte, mostrando, uma vez mais, clara relação com a redução na taxa de desemprego e, provavelmente, com o referido Plan 500.000 de Hollande, adotado no início de 2017 e já em plena execução no quarto trimestre do ano.

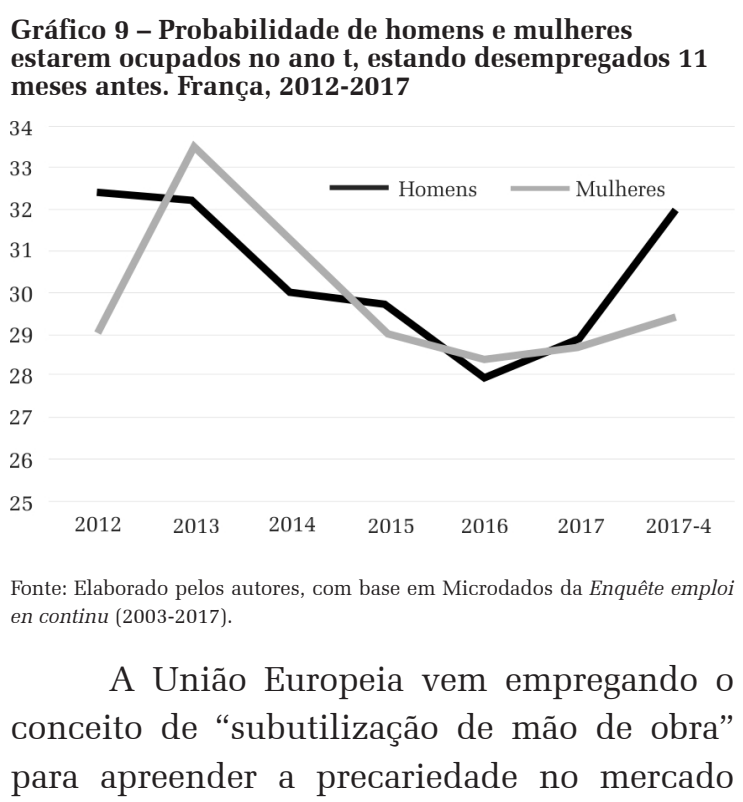


de trabalho. O conceito inclui pessoas desempregadas (procuravam ativamente emprego), subocupadas (trabalhavam em tempo parcial e gostariam de trabalhar mais horas), e o que a UE define como "halo do desemprego", ou seja, pessoas inativas que gostariam de trabalhar, mas não estavam disponíveis para isso nas duas semanas anteriores, ou que queriam trabalhar, mas já não procuravam emprego (INSEE, 2019). O Gráfico 10 apresenta o movimento desse indicador no caso da França. ${ }^{34}$

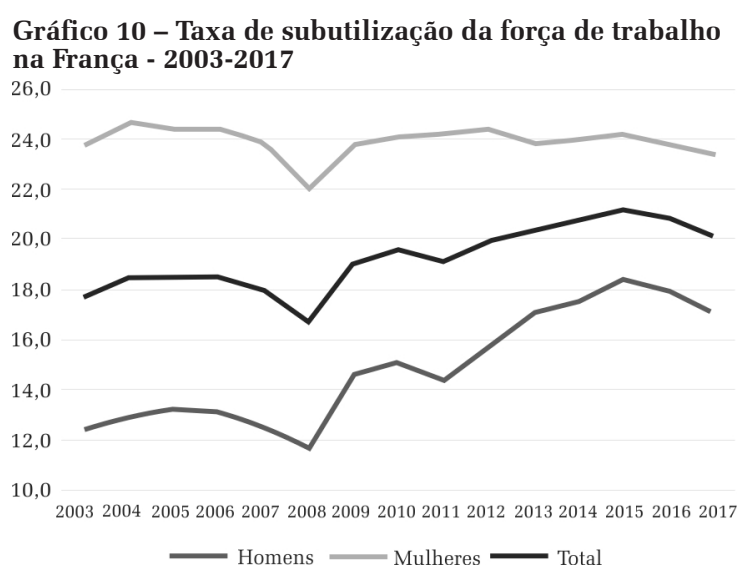

Fonte: Elaborado pelos autores, com base em Microdados da Enquête emploi en continu (2003-2017).

A evolução da subutilização da mão de obra segue a mesma tendência das duas dimensões analisadas antes. Vemos importante ponto de inflexão em 2008, quando a taxa atinge seu menor valor no período (22\% para as mulheres e $12 \%$ para os homens), passando a aumentar quase constantemente no caso deles, até atingir mais de $21 \%$ em 2015, crescimento importante de 9 pontos percentuais, decrescendo levemente nos dois anos seguintes. Todas as dimensões da subutilização aumentaram no caso deles, sendo que o desemprego respondeu por $35 \%$ da variação. Não há ele-

${ }^{34}$ Infelizmente a PNADC só permite construir esse indicador para o Brasil de forma comparável com a França a partir de 2016. Entre 2012 e 2015 só há informação sobre subocupação por insuficiência de horas efetivamente trabalhadas. A partir de 2016 introduziu-se o conceito de horas habitualmente trabalhadas, como na França. O impacto dessa mudança na taxa de subutilização de mão de obra foi de mais de 5 pontos percentuais, impedindo a comparação com anos anteriores. No quarto trimestre de 2018 as taxas foram de $25,5 \%$ para as mulheres e $18,5 \%$ para os homens. Semelhantes, pois às encontradas na França. mentos para se afirmar se a reversão recente terá ou não continuidade, já que, como ocorreu com os outros indicadores, a subutilização masculina parece estar estreitamente relacionada com a variação no ciclo econômico. No caso das mulheres, se desconsiderarmos 2008, a taxa variou muito pouco em torno na média de $24 \%$, sendo, portanto, indiferente ao ciclo econômico e, ao que parece, às reformas ou políticas de emprego.

Esses três indicadores são coerentes, ainda, com a duração do desemprego dos homens, embora não tanto das mulheres. Os Gráficos 11 e 12 mostram a evolução desse indicador nos últimos 15 anos para os dois sexos. Uma vez mais é evidente o efeito da crise financeira de 2008 nas chances de ambos. A categoria que revela mais claramente esse efeito é a de pessoas entre 3 meses a 1 ano em situação de desemprego. Ela cresceu cinco pontos percentuais entre 2008 e 2009, retornando apenas ao patamar de 2006 a partir de então, patamar 5 pontos percentuais mais alto do que o dos anos anteriores. Ou seja, a crise alongou um pouco a permanência no desemprego por parte de pessoas que antes ficavam nessa condição por menos de 3 meses, atingindo, pois, principalmente os desempregados recentes.

A partir de 2013, vemos fenômeno novo na janela temporal de interesse aqui. Em linha com a taxa de desemprego e a probabilidade de se conseguir um emprego por parte dos desempregados homens, aumenta constantemente a participação dos que estavam nessa condição há três anos ou mais, com leve retração em 2017. No pico do período (2016), a proporção deles como desempregados de longa duração atingiu 16,5\%, contra 10,8\% em 2013. A leve reversão em 2017 (queda de 1,7 ponto percentual) é compatível com a redução na taxa de desemprego no caso deles, mas continuou alta a proporção de homens desempregados há muito tempo, e a reversão não ocorreu entre as mulheres. O desemprego de longa duração, no caso delas, cresce constantemente desde 2013, saindo de pouco menos de $10 \%$ para atingir 
13,5\%. Temos, então, redução progressiva na participação das outras faixas de tempo de desemprego, sobretudo o desemprego de curta duração (menos de três meses), que cai até 2016; e aumento do desemprego de longa duração. Nesse último caso, indiferente ao ciclo econômico, ao menos no caso delas.

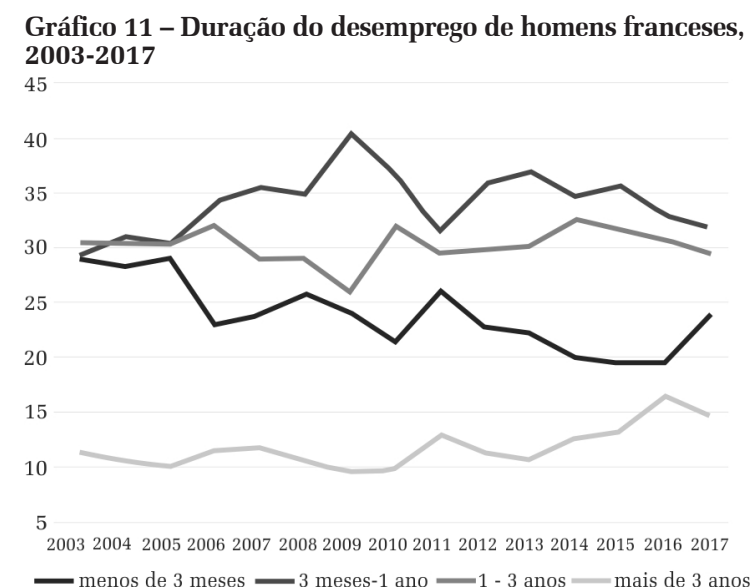

Fonte: Elaborado pelos autores, com base em Microdados da Enquête emploi en continu (2003-2017).

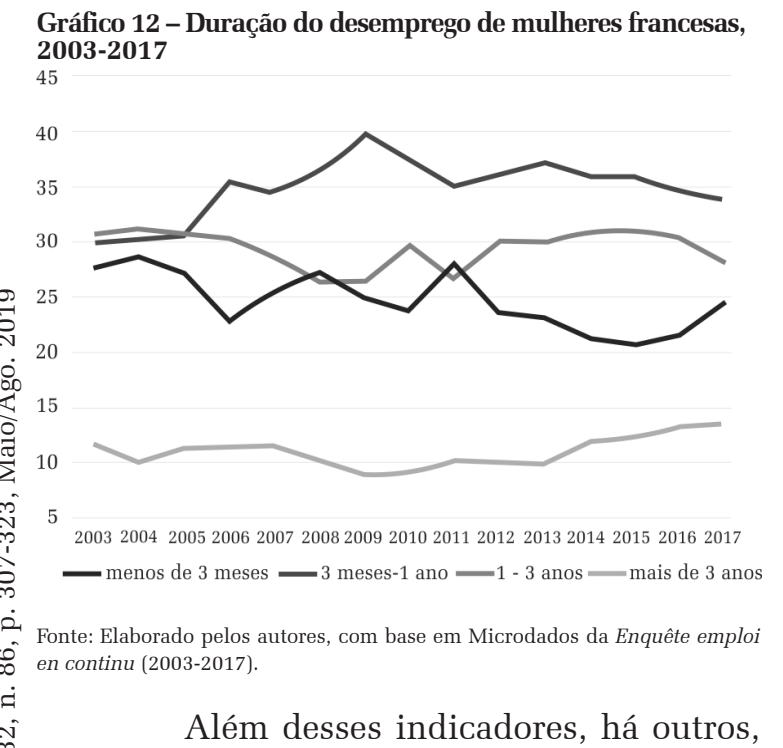
menos centrais, mas igualmente importantes, que apontam para a lenta, mas contínua deterioração dos contratos de trabalho de parte F (minoritária, é bom frisar) dos franceses. Por exemplo, vem aumentando a participação dos contratos por tempo parcial, nos quais apenas $5,7 \%$ dos homens participavam em 2003, proporção que subiu quase constantemente a cada ano, até atingir mais de 10\% em 2017. Trata-se, pois, de mudança de mais longo prazo, semelhante àquela da redução dos contratos CDI. E o aumento nos contratos em tempo parcial é muito forte entre os homens mais jovens, de 15 a 29 anos (saindo de $15 \%$ para mais de $20 \%$ no período) e entre os com 60 anos ou mais, subindo de $24 \%$ a quase $36 \%$. Entre as mulheres, a variação é pequena, em torno da média de $30 \%$, sendo indiferente ao ciclo econômico. Em qualquer caso, como as alterações são lentas e persistentes, não parecem sofrer efeitos diretos das mudanças recentes na legislação trabalhista.

\section{CONCLUSÃO}

Apesar das profundas diferenças nas histórias culturais, sociais, legislativas e econômicas dos dois países, as reformas recentes nas legislações trabalhistas de Brasil e França abriram uma porta para a comparação. A rationale que as presidiu tem inspiração comum: a flexibilização das formas de uso do trabalho, em países nos quais a legislação era reputada muito rígida, dificultando o ajuste das empresas às mudanças constantes na competitividade mundial. Brasil e França ocupam lugares muito distintos na divisão internacional do trabalho, e sofrem pressões competitivas também distintas, mas os motivos alegados pelos reformadores dos dois lados são espantosamente semelhantes. Modernização das relações de trabalho, geração de empregos (e combate ao desemprego), crescimento econômico, melhoria da renda dos trabalhadores e das condições de trabalho, são essas as promessas comuns das duas reformas. Os meios para atingi-las, contudo, parecem apontar na direção oposta: flexibilização dos contratos de trabalho, redução dos custos de demissão, redução de direitos inscritos em lei, individualização das relações contratuais, multiplicação de formas contratuais precárias e instáveis, desconsidera- 
ção dos corpos intermediários e dos sindicatos, o que os leva a buscar formas de revitalização diante do número declinante de seus membros. A promessa de segurança socioeconômica vem acompanhada de formas de regulação que geram, na verdade, insegurança no emprego, na renda e nos direitos trabalhistas.

As reformas são muito recentes, e embora estabeleçam claro corte temporal com o passado, sobretudo no caso do Brasil, os indicadores para 2018 sugerem que, se há efeitos visíveis, eles vão na contramão no pretendido pelas reformas de 2017. O desemprego não foi revertido, a informalidade cresceu, as chances dos jovens no mercado de trabalho não melhoraram e a chance de um desempregado num ano encontrar um emprego no ano seguinte tampouco melhorou.

No caso da França, a Loi Travail e as Ordonnances de Macron se somam a um edifício em construção desde os anos 1980, com um aprofundamento na primeira década dos anos 2000 e, principalmente, após a crise de 2008. Ainda é cedo para afirmar que elas marcam uma ruptura. Os movimentos recentes, de 2016 e 2017, parecem sofrer menos o efeito de novas regras do que de mudanças de mais longo prazo nas estratégias das empresas, que vêm flexibilizando lenta, mas constantemente uma proporção cada vez maior de seus contratos de trabalho. O crescimento dos contratos CDD e dos contratos CDI em tempo parcial, sobretudo entre os homens mais jovens, é constante desde pelo menos a crise de 2008. O desemprego e a subutilização de mão de obra, especialmente no caso dos homens, parecem responder mais de perto ao ciclo econômico e, se houve efeito visível nos últimos anos, parece ter sido o do Plan 500.000 de Hollande, que colocou, "na ativa", desempregados, entre outros que participaram de cursos de requalificação a partir de 2017. Ainda assim, mesmo considerando que a taxa de subutilização de mão de obra esteja na faixa dos $20 \%$ da população economicamente ativa (21,5\% no Brasil), as mudanças estão muito longe de aproximar a realidade francesa da brasileira. Se elas apontam para maior precariedade, ela atinge franja ainda minoritária (embora cres- cente) do mercado de trabalho, particularmente os mais jovens e os mais velhos, e o país está muito longe de tornar informais vínculos ainda regulados por leis, contratos e acordos coletivos de trabalho.

As mudanças legais levam um tempo para ser adotadas pelas empresas. Demoram a "pegar". Mas como, nos dois países, as mudanças representam redução substancial dos custos do trabalho, devemos esperar, em curto espaço de tempo, impactos importantes na configuração dos contratos de trabalho e nas chances de homens e mulheres, jovens e adultos, nos mercados de trabalho dos dois países.

Recebido para publicação em 22 de abril de 2019 Aceito em 24 de maio de 2019

\section{REFERÊNCIAS}

AMADEO, E.; PERO, V. Adjustment, stabilization, and the structure of employment in Brazil. Journal of development studies, n. 36, p. 120-148, 2000.

APPAY, B. La dictature du succès: le paradoxe de l'autonomie contrôlée et de la précarisation. Paris: L'Harmattan, 2005.

BENSUSÁN, G. (Coord.). Instituições trabalhistas na América Latina: desenho legal e desempenho real. Rio de Janeiro: Revan, 2006. p. 285-366.

BOUfFARTIGUE, P.; BUSSO, M. Précarité, informalité: une perspective Nord-Sud pour penser les dynamiques des mondes du travail. Les mondes du travail: formes et dynamiques du travail informel, 9-10, p. 27-39, juin. 2009. BOYER, R. (Dir.). La flexibilité du travail en Europe. Paris: La Découverte, 1987.

BRAGA, R. A rebeldia do precariado: trabalho e neoliberalismo no Sul global. São Paulo: Boitempo, 2017.

BRASIL. Projeto de Lei n. 6787, de 23 de dezembro de 2016. Altera o Decreto-Lei $n^{\circ} 5.452$, de $1^{\circ}$ de maio de 1943 -
Consolidação das Leis do Trabalho, e a Lei $n^{\circ} 6.019$, de 3 de janeiro de 1974, para dispor sobre eleições de representantes dos trabalhadores no local de trabalho e sobre trabalho temporário, e dá outras providências. Brasília: Câmara dos Deputados, 2016. Disponível em: https://www.camara.leg.br/ proposicoesWeb/fichadetramitacao?idProposicao $=2122076$. Acesso em: 18 jan. 2019.

BRASIL. Lei n. 13.429, de 31 de março de 2017. Altera dispositivos da Lei n. 6.019, de 3 de janeiro de 1974, que dispõe sobre o trabalho temporário nas empresas urbanas e dá outras providências; e dispõe sobre as relações de trabalho na empresa de prestação de serviços a terceiros. Brasília: Casa civil, 2017. Disponível em: http://www. planalto.gov.br/ccivil_03/_ato2015-2018/2017/lei/L13429. htm. Acesso em: 21 jan. 2019.

CACCIAMALI, M. C. Um estudo sobre o setor informal urbano e formas de participação na produção. 1982. Tese (Doutorado) - Faculdade de Economia, Administração e Contabilidade, Universidade de São Paulo, São Paulo, 1982. 
CARDOSO, A. Informality and public policies to overcome it: the case of Brazil. Sociologia \& Antropologia, v. 6, p. 321-349, 2016a.

CARDOSO, A. Work in Brazil: essays in historical and economic sociology. Rio de Janeiro: EdUERJ, 2016b.

CARDOSO, A. A construção da sociedade do trabalho no Brasil: uma investigação sobre a persistência secular das desigualdades. 2. ed. Rio de Janeiro: Amazon, 2019.

CARELLI LACERDA, R.; CASAGRANDE, C. Reforma trabalhista: reflexões críticas. Rio de Janeiro: Editora Lumen Juris, 2018.

CASTEL, R. Refaire société. Paris: La République des idées, 2011.

CINGOLANI, P. La précarité. 5. ed. Paris: PUF, 2017.

DAL ROSSO, S. A jornada de trabalho na sociedade. Brasília: UnB, 1997.

DE BONY, J. Licenciement transactionnel. In: BUREAU, M.C.B.; CORSANI, A.; GIRAUD, O; REY, F. (Dir.). Les zones grises des relations de travail et d'emploi: un dictionnaire sociologique. Buenos Aires: Teseo, 2019. p. 293-302. Disponivel em https://teseopress.com/ dictionnaire

DE LA GARZA, E. La flexibilidad del trabajo en América Latina. Revista latinoamericana de estudos do trabalho, v. 3, n. 5, p. 129-157, 1997.

DEMAZIÈRE, D.; GUIMARÃES, N. A.; HIRATA, H.; SUGITA, K. Être chômeur à Paris, São Paulo et Tokyo. Une méthode de comparaison internationale. Paris: Presses de Sciences Po, 2013. (Coll. Académique).

DRUCK, M. G. Trabalho, precarização e resistências. Caderno CRH, Salvador, v. 24, p. 35-54, 2011.

GUITTON, C.; MARUANI, M.; REYNAUD, E. (Ed.). L'emploi en Espagne. Marché du travail et relations professionnelles. Paris: Syros, 1991.

INSTITUT DE RECHERCHES ECONOMIQUES ET SOCIALES (IRES). Renouveau syndical: enjeux, stratégies et pratiques. Chronique internationale, n. 159-160, sept./ dec. 2017. Numéro spécial.

INSTITUT NATIONAL DE LA STATISTIQUE ET DES ÉTUDES ÉCONOMIQUES (INSEE). Enquête Emploi en continu. 2017. Disponível em: http://bdq.quetelet.progedo. fr/fr/Details_d_une_enquete/1950. Acesso em: 2 abr. 2019.

INSTITUT NATIONAL DE LA STATISTIQUE ET DES

- ÉTUDES ÉCONOMIQUES (INSEE). La France dans

l'Union européenne. 2019. Disponível em: https://www. . insee.fr/fr/statistiques/fichier/3901943/FR-UE_19_VE.pdf.

\& Acesso em: 28 maio 2019.

$\overleftrightarrow{\Delta}$

INSTITUTO BRASILEIRO DE GEOGRAFIA E ESTATISTICA

$\sum^{\pi}$ (IBGE). Pesquisa Nacional por Amostra de Domicílios

$\angle$ Contínua. Notas metodológicas. Rio de Janeiro: IBGE,

กิ 2014. Disponível em: ftp://ftp.ibge.gov.br/Trabalho e,

$\%$ Rendimento/Pesquisa Nacional_por Amostra_de-

ô Domicilios_continua/Notas metodoTogicas/notas m metodologicas.pdf. Acesso em: 7 mar. 2019.

$\dot{2}$

$\odot$ LA RUPTURE conventionnelle collective. 2019. $\infty$ Disponível em: https://travail-emploi.gouv.fr/droit-du-

¿ travail/la-rupture-du-contrat-de-travail/article/la-rupture-

if conventionnelle-collective. Acesso em: 2 abr. 2019.

$>$ LÉGÉ, P. Projection et légitimation d'une réforme: le "projet ô de loi travail”. Paris: éditions du Croquant, 2019.

LEITE, M. P. "El trabajo en el Brasil de los años 2000: dos స్ caras de un mismo proceso". In: PAEZ, C. S.; ROMERO, L. Q.; EGURROLA, J. I. (Org.). Trabajo y explotación en İ América Latina: Brasil y Mexico. Ciudad de México: Plaza y Valdés, 2014. p. 65-86.

MACEDO, E.; CHAHAD, J. P. Z. O FGTS e a rotatividade. São Paulo: Loyola, 1985

త MARUANI, M.; REYNAUD, E.; ROMANI, C. (Dir.). La flexibilité enItalie. Paris: Syros Alternatives, 1989.

MENEZES FILHO, N. A situação dos jovens "nem-nem". 2013. Disponível em: https://www.insper.edu.br/noticias/asituacao-dos-jovens-nem-nem/. Acesso em: 13 mar. 2019.

MINÉ, M. Quand le droit favorise l'augmentation et la flexibilité du temps de travail. La nouvelle revue $d u$ travail, p. 17-32, 2017a. Disponível em: http://journals. openedition.org/nrt/3234. Acesso em: 17 abr. 2019. DOI: 10.4000/nrt.3234. 11 mis en ligne le 03 novembre 2017.

MINÉ, M. Droit du travail: la hiérarchie des normes est-elle inversée? The conversation, 26 sept. 2017b. Disponível em: https://theconversation.com/droit-du-travail-la-hierarchiedes-normes-est-elle-inversee-84548. Acesso em: 21 abr. 2019.

NORONHA, E. G. Entre a lei e a arbitrariedade: mercados e relações de trabalho no Brasil. São Paulo: LTr, 2000.

NOVA ADI questiona trabalho intermitente instituído pela Reforma Trabalhista. 2017. Disponível em: http://stf.jus.br/portal/cms/ verNoticiaDetalhe.asp?idConteudo=363898\&amp;caixaBusca $=\mathrm{N}$. Acesso em: 13 mar. 2019.

OLIVEIRA, R. V. de; TARGINO, I. (Org.). Marchas e contramarchas da informalidade do trabalho: das origens às novas abordagens. João Pessoa: Editora Universitária, 2011.

PAUGAM, S. Le salarié de la précarité. Paris: PUF, 2000.

PAUGAM, S. La disqualification sociale: essai sur la nouvelle pauvreté. 4. ed. Paris: PUF, 2009.

PERO, V. Terciarização e qualidade do emprego: uma análise da região metropolitana de São Paulo no início dos anos 90. In: ENCONTRO NACIONAL DE ECONOMIA, 23., 1995, Salvador. Anais [...] Salvador: [S.n.], 1995. v. 2, p. 560-580.

QUATREMER, J. Loi travail: un texte en service recommandé par Bruxelles? 2016. Disponível em: https://www.liberation.fr/ france/2016/06/12/loi-travail-un-texte-en-service-recommandepar-bruxelles_1458974. Acesso em: 13 mar. 2019.

QUIJOUX, M. Conflits du travail. Les zones grises des relations de travail et d'emploi: un dictionnaire sociologique. Buenos Aires: Teseo, 2019. p. 61-69.

REY, M. Ordonnances Travail: ce qui a marché... ou pas. 2018. Disponível em: https://lentreprise.lexpress.fr/rhmanagement/droit-travail/ordonnances-travail-ce-qui-amarche-ou-pas 2034499.html. Acesso em: 15 mar. 2019.

RINALDI, C.; SILVA, C. Número de ações trabalhistas cai 40\% em seis meses. 2018. Disponível em: https://economia. uol.com.br/noticias/estadao-conteudo/2018/06/22/ numero-de-acoes-trabalhistas-cai-40-em-seis-meses.htm. Acesso em: 15 mar. 2019.

ROCHA, R.; ULYSSEA, G.; RACHTER, L. Do lower taxes reduce informality? Evidence from Brazil. Journal of development economics, v. 134, p. 28-49, 2018.

SERVICE PUBLIC (FRANÇA). Fin d'un contrat à durée déterminée (CDD). [20--]. Disponível em: https://www.servicepublic.fr/particuliers/vosdroits/F40. Acesso em: 8 maio 2019.

SILVA, S. G. C. L. Relações coletivas de trabalho: configurações institucionais no Brasil contemporâneo. São Paulo: LTr, 2008.

STANDING, G. The precariat: the new dangerous class. London: Bloomsbury, 2011.

TEIXEIRA, M. O. et al. Contribuição crítica à reforma trabalhista. Campinas, 2017. Disponível em: http://www. eco.unicamp.br/images/arquivos/Reformatrabalhista.pdf. Acesso em: 15 nov. 2018.

TRADE union membership and organising in Europe. Transfer, v. 23, n. 1, 2017.

TRIPIER, P. La sociologie du travail à travers ses paradigmes. In: DE COSTER, M.; PICHAULT, F. Traité de sociologie du travail. 2. éd. Paris: De Boeck Supérieur, 1998. (Ouvertures sociologiques). p. 41-59. 


\section{LABOR REFORMS AND THEIR MARKETS: a comparison Brazil-France}

\author{
Adalberto Cardoso \\ Christian Azaïs
}

Recent reforms in labor legislation in Brazil and France have opened a door for comparison. The rationale behind them has a common inspiration: flexibilization of forms of labor use in countries where legislation was considered very rigid, making it difficult for companies to adjust to constant changes in global competitiveness. Although Brazil and France occupy very different places in the international division of labor, and face different competitive pressures, the motivation of the reformers on both sides are strikingly similar. Modernization of labor relations, job creation, reduction of unemployment, economic growth, improvement of workers' income and working conditions. But the promise of socioeconomic security is accompanied by forms of regulation that actually generate insecurity in employment, income, and labor rights. The study tries to evaluate some dimensions of this insecurity, comparing the two countries around the notion of "precariousness".

KeYwords: Brazil. France. Labor reform. Socioeconomic insecurity. Precariousness.

\section{LES REFORMES DU TRAVAIL ET LEURS MARCHES: une comparaison Brésil-France}

\author{
Adalberto Cardoso \\ Christian Azaïs
}

Les réformes récentes de la législation du travail au Brésil et en France ont ouvert une porte à la comparaison. Elles sont inspirées par une logique commune : la flexibilisation des formes d'utilisation de la main-d'œuvre dans des pays où la législation était considérée comme très rigide, empêchant les entreprises de s'adapter aux changements de la compétitivité mondiale. Bien que le Brésil et la France occupent des positions très distinctes dans la division internationale du travail avec des pressions concurrentielles différentes, les motivations des réformateurs des deux côtés sont remarquablement similaires. Modernisation des relations de travail, création d'emplois (et lutte contre le chômage), croissance économique, amélioration du revenu et des conditions de travail des travailleurs. Mais la promesse de sécurité socio-économique s'accompagne de formes de régulation qui génèrent effectivement une insécurité en matière d'emploi, de revenu et de droits du travail. L'étude évalue certaines dimensions de cette insécurité en comparant les deux pays autour de la notion de "précarité”.

MotS-CLÉs: Brésil. France. Réforme du travail. Insécurité socioéconomique. Précarité. 
